\title{
ANALYSIS OF THE IMPLICATIONS OF THE USSR PROVIDING REPROCESSING AND MOX FABRICATION SERVICES TO OTHER COUNTRIES
}

(Summary)

\section{The Problem}

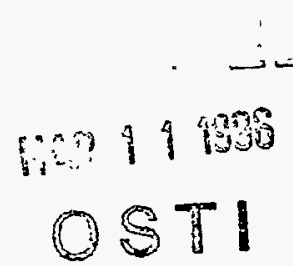

The enclosed brief analysis, which is based on unclassified sources, seeks to identify what some of the implications would be if the Soviets started to move actively to try to provide reprocessing and MOX fabrication services to the U.S. and other countries. While information on Soviet intentions is limited, it postulates that the Soviets would offer to reprocess spent LWR at competitive prices, fabricate the plutonium and reenrich the uranium, and sell these products back to the customer. Since it is not known whether they would insist on returning the waste from reprocessing or would be prepared to keep it, we comment briefly on what the implications of either of these actions might be.

\section{Discussion and Conclusions}

\section{A. Use of Such Services by U.S. Utilities}

Under the terms of the Atomic Energy Act, it would not be feasible to transfer U.S. spent fuel to the USSR for reprocessing unless this occurs pursuant to an appropriate agreement for cooperation under Section 123 of the Act." The U.S. has no such bilateral agreement in force with the USSR and the negotiation and conclusion of such an arrangement could be a time consuming and possibly controversial affair - especially during this period of instability in the USSR. Over the longer term one cannot rule out such a possibility. Legally, however, even if they were interested, U.S. utilities could not now avail themselves of a Soviet reprocessing offer.

Beyond this, it is questionable, for substantive reasons, whether U.S. utilities would now be very interested, in accepting a Soviet reprocessing and MOX fabrication offer along the lines described. The utilities might be fearful that acceptance of a Soviet offer would undercut the DOE repository program which they have strongly supported. They also should have little economic incentive to turn to reprocessing in the USSR so long as the Federal Government is prepared to take spent fuel off their hands in return for their 1 mill per $\mathrm{KwH}$ contribution to the Nuclear Waste fund. Moreover, the proposition of initiating a

- While in theory, the U.S. could transfer spent U.S. fuel to the USSR under the auspices of the U.S. Agreement for Cooperation with the IAEA this is unlikely to be a practicable or very expeditious route to follow. 
MOX recycle program in light water reactors would raise several economic and policy questions. Economically, the U.S. utilities might view plutonium to have a negative value and it can be expected that strong opposition to plutonium recycling would surface from elements in the U.S. environmental and arms control communities. Before any such step is taken some will argue that there should be a full-blown environmental impact statement prepared - along the lines of the GESMO review that was held in the 1970's.

On the other hand, some U.S. utilities might look with increasing favor on a Soviet offer if the Russians are prepared to keep the reprocessing wastes, if it looks like the U.S. repository program is doomed to indefinite delay and frustration, if the Soviet prices are significantly cheaper than European reprocessing charges, and if the utilities involved could be exempted from making further contributions to the U.S. Nuclear Waste Fund. One also could ease any opposition to a Soviet offer if the proposition of recycling the MOX in U.S. light water reactors were deferred for now - with the idea that the plutonium would be returned to the U.S. for storage, and safe keeping pending decisions on use.

\section{B. Application of Soviet Services to U.S. "Origin" Nuclear Materials Located in Third Countries}

Under the terms of U.S. civil nuclear agreements with other countries, special nuclear materials received from the U.S. or plutonium derived therefrom cannot be retransferred to another country without U.S. permission. Moreover, the U.S. has taken the position that such concurrence cannot be granted unless the U.S. has an appropriate agreement in force with the receiving country involved (in this case the USSR). Thus, Japanese spent fuel of U.S. origin can not go to the USSR for reprocessing unless the U.S. concurs beforehand and unless the U.S. has in force an appropriate Agreement for Cooperation with the USSR. The nuclear trade press has mentioned Japan as one of the countries that the USSR has been sounding out on the provision of MOX fabrication services.

The U.S. policy and attitudes towards concurring in the retransfer of "U.S. controlled" spent fuel to the USSR for reprocessing most likely would vary with the cooperating country involved and would be heavily influenced by whether it was contemplated that MOX would be returned to the originating country. It would seem likely that (if an appropriate agreement for cooperation were in force), that the U.S. would concur in retransfer of Japanese or Swiss spent fuel to the USSR for reprocessing as well as in the return of MOX to those nations. The U.S. has concurred in numerous transfers of Swiss and Japanese spent fuel to Euratom for reprocessing as well as plutonium returns to both countries. Also, the effects of such transactions would be minimal from a non-proliferation perspective since both countries already are extensively involved in the utilization of reprocessing services as and plutonium.

On the other hand, the U.S. has strongly encouraged both Taiwan and South Korea to remain on a "once through" fuel cycle and to refrain from any indigenous reprocessing or plutonium use programs. This has been due to a variety of non-proliferation considerations, 
including the sensitive strategic location of both countries. Thus, it is unlikely that the U.S. would be prepared to concur in the retransfer from Taiwan or South Korea of U.S. origin spent fuel to the USSR for reprocessing if this was tied to an arrangement visualizing any plutonium returns to either country.

C. To What Extent are Soviet Reprocessing and MOX Fabrication Services Likely to be Made Available to Other Countries?

This raises the question of what the Soviet policies are likely to be in extending reprocessing and MOX fabrication services to other countries with whom the U.S. currently has no nuclear or political relationship.

There are several possible countries in this category, including Cuba, Iran, Argentina, Brazil, and Libya. In the event the Soviets are serious about marketing reprocessing and MOX fabrication services to other nations, it would be desirable at an early stage, to learn (through diplomatic channels) of what criteria they have in mind as to who they might elect to deal with and under what conditions. In some cases it might make a constructive contribution to non-proliferation objectives if they were prepared to take spent fuel out of a nation without returning any plutonium. However, in other cases it could be provocative and destabilizing if they visualized returning plutonium to a given country - Libya and Iran being good examples.

In general, the Soviets have been solid supporters of non-proliferation values and they have worked cooperatively with the U.S. in support of such objectives as the NPT and IAEA safeguards. However, it will be important to watch carefully whether the recent break-up in the USSR will lead to any erosion of effective governmental nuclear export control. Also, it will be important to observe whether the efforts to build a market economy and to earn hard currencies will lead to any compromise of Soviet non-proliferation principles in the interest of gaining commercial benefits. 


\section{ANALYSIS OF THE IMPLICATIONS OF THE USSR PROVIDING REPROCESSING AND MOX FABRICATION SERVICES TO OTHER COUNTRIES}

\section{The Problem}

In recent months there have been reports and rumors to the effect that the Soviets are positioning themselves to offer to reprocess spent fuel received from cooperating countries, fabricate the recovered plutonium into mixed oxide fuel, reenrich the recovered uranium, and sell these materials back to utilities. Little is known about the financial terms that would be involved but this paper assumes that the Soviets would insist on being paid in hard currencies and that the costs of these reprocessing services might be as high as (or possibly a little less than) the cost of European reprocessing services, which translates to about 6 to 8 mills per/KWH. It is not known if the Soviets would be prepared to keep the reprocessing waste that would be involved or would insist on returning it to the originating country.

This paper briefly discusses several of the major implications of the Soviet "offer" in terms of (a) the effects if it were extended to U.S. utilities; (b) the implications if it were extended to special nuclear materials in third countries that are subject to U.S. controls and consent rights in third countries ; and (c) the consequences if it were also extended to and accepted by other countries with whom the U.S. does not have an Agreement for Cooperation (Cuba, Iran, India, Argentina, Brazil, etc.).

\section{Discussion}

Only a very limited amount of information on the USSR "offer" has surfaced, but, if it is real

\footnotetext{
- Mostly U.S. origin special nuclear materials or plutonium derived therefrom.
} 
it seems calculated to strengthen the Soviet position as a nuclear supplier, bearing in mind the major in-roads the USSR already has made in the field of enrichment.

\section{A. Application to U.S. Utilities}

At the present time it seems doubtful whether the Soviet initiative will develop into any thing very tangible with any U.S. utilities in the nearer term, for a variety of reasons, including the following:

it is hard to see why any U.S. utility would be seriously interested in pursuing the Soviet offer so long as DOE has the contractual responsibility (as well as a programmatic effort underway) to take spent fuel off a utility's hands pursuant to the Nuclear Waste Policy Act. The costs involved in using the Soviet services presumably would be materially greater than the 1 mill/KWH that the utilities are now obliged to continue to contribute to the Nuclear Waste Fund. On the other hand, the utilities might obviously take a more positive attitude towards a Soviet offer if it appears (because of problems confronting the DOE repository program and the MRS), that DOE might be unable to implement its contractual responsibilities to accept spent fuel. Even here, however, much would depend on whether the Soviets would insist on returning the radioactive wastes or would be prepared to keep them. If the Soviets returned the wastes, the U.S. utilities involved still would have to depend on DOE to get a repository going. However, if the Soviets agreed to store the wastes U.S. utility interest obviously could be greater but ultimately would still depend, in any part, on any continuing obligation to fund the repository program. Also, the U.S. utilities have generally been strong supporters of the repository program and might not be inclined to conclude such arrangements with the Soviets unless they had the full blessing of the 


\section{U.S. Government.}

- from a legal standpoint, U.S. special nuclear material could only be transferred to the USSR for reprocessing or any other purpose pursuant to an agreement for cooperation concluded pursuant to Section 123 of the U.S. Atomic Energy Act." While the Soviets have expressed an interest (to DOE Deputy Secretary Moore), in concluding a civil nuclear agreement with the United States, none is now in force and the conclusion of such an agreement could prove to be a timeconsuming and possibly controversial affair. Until such an agreement comes into effect, no U.S. origin spent fuel could readily be sent to the USSR for reprocessing either from U.S. utilities or (if the material is subject to U.S. controls and consent rights) from third countries (like Japan) with whom we have agreements for cooperation. Approval by the President would be required following which the Agreement would have to rest before the Congress for 90 days before coming into effect. There would likely be close Congressional scrutiny of such a proposed nuclear agreement with the USSR, including an examination of such questions as to whether it is prudent to move in this direction given the current state of disarray in the USSR, whether the shipment of U.S. spent fuel to the USSR would seriously undercut the U.S. geologic waste repository program (which it well might), and whether the controls over the separated plutonium in the USSR pending its return to the U.S. would be adequate. The agreement also might be attacked by those elements in the Congress who have claimed that the Soviets have been "dumping" enriched uranium into the U.S. market at

"This assumes that neither the U.S. nor the USSR would find it very practicable to employ the U.S. Agreement for Cooperation with the International Atomic Energy Agency as a vehicle for transferring U.S. spent fuel to the USSR since presumably such transfers would have to be approved by the IAEA Board of Governors on a project-by-project basis. 
artificially low prices. Simply put, they might judge a new agreement with the USSR to be too supportive to Soviets aspirations to be a more active and competitive nuclear supplier.

The disposition of the plutonium also is likely to be a sensitive matter regardless if it is returned to the U.S. in MOX form for recycling in light water reactors, transferred with U.S. permission to third countries for similar use, or retained for civil uses in the USSR. Most likely, there would be some strong opposition to the proposition of returning the plutonium in MOX form for thermal recycling in the U.S.. In the first instance U.S. utilities might not find this to be an attractive option economically even if the plutonium is assumed to be a "free good" that comes with reprocessing. This is because some believe that the real effective value of the plutonium for thermal recycle is likely to be negative due to the comparative high costs of fabricating MOX fuel compared to enriched uranium. Currently since there is no commercial U.S. MOX fabrication industry the U.S. utilities involved might have to depend on off-shore fabricators or conceivably some special assistance from the Federal Government might be required to help get a domestic fabrication industry going. Moreover, even if one were able to overcome the economic obstacles it can be expected that elements in the U.S. arms control or environmental communities might strongly oppose any major moves towards plutonium recycling in U.S. LWR's on the grounds that this would be harmful to non-proliferation objectives to the extent it might serve to encourage additional foreign countries to move to plutonium use. Most likely opponents would argue that a major "environmental" review (along the line of the GESMO review of the mid 1970's) should first take place before any import or operative license authorizing MOX use is allowed. Also, the U.S. light water reactors that would be candidates for recycling would 
have to have their licenses amended for such purposes and these amendments could be subject to challenge by interested environmental groups. On the other hand, if some of the plutonium to be returned to the U.S. were earmarked for "burning" and consumption in future liquid metal reactors like the IFR (and if the prospects for the IFR appeared promising) this conceivably could ease the situation. The degree of opposition to the Soviet reprocessing offer also could be softened if no decision were taken for now as to whether the U.S utility industry should initiate a major MOX recycle program. In this case, the plutonium could be returned to the U.S. for storage (possibly in oxide form) awaiting decisions as to subsequent disposition.

An alternative to a return of the plutonium to the U.S. would be for the material to be sold to third countries with whom the U.S. has appropriate agreements for cooperation and with prior U.S. governmental permission of the retransfers. In this case any net revenues from such sales presumably would flow to the U.S. utilities involved. Also, pending sale, the material would have to be stored and protected in accordance with measures, including safeguard measures acceptable to the U.S. Whether there is a market capable of sustaining sufficiently attractive prices for this $\mathrm{Pu}$ is another matter.

As still a further possibility, the U.S. Government and U.S. utilities might allow the USSR to keep the plutonium involved. While one might argue that such a move would be entirely defensible given the vast quantities of plutonium that the Soviets have at their disposal others might challenge the prudence of such a move given the high instability and uncertainty that is being witnessed in the USSR following the August coup. 
On balance, it is the conclusion of this preliminary assessment that the rumored Soviet "offer" of reprocessing and MOX fabrication services is unlikely to have any strong appeal to U.S. utilities unless the costs involved to them prove highly attractive, and unless they really become convinced that the Federal Government is apt to default on its spent fuel acceptance obligations under the Nuclear Waste Policy Act. In this case, the political acceptability of the arrangement might be improved if the issue of recycling MOX in U.S. light water reactors were deferred with the idea that the plutonium would be returned and stored in the U.S. in suitable form.

\section{B. The Application of Soviet Reprocessing and MOX Fabrication Services to Special Nuclear Materials In Third Countries Subject to U.S. Controls}

Presumably, the Soviets might also seek to offer these fuel cycle services to third countries like Japan or Switzerland that possess special nuclear material of U.S. origin that they might wish to have reprocessed on the assumption that the MOX would be returned to them and recycled in their light water reactors. Indeed, the reports in the trade press about this possible new Soviet service (enclosed as Annex A) identified Japan as a possible first marketing target. The U.S. already has given approval on several occasions to Japanese and Swiss spent fuel of U.S. origin being sent to COGEMA and BNFL for reprocessing (via the U.S.-Euratom Agreement for Cooperation) and has agreed to returns of MOX to those same countries. The difficulty here, however, is that the U.S. has consistently taken the position that special nuclear materials of U.S. origin or plutonium derived therefrom cannot be retransferred to a third country (in this case the USSR) unless U.S. permission is first given and the U.S. has a suitable agreement for cooperation in effect with the nation that is to receive the material (USSR). This concept of "prior consent" has been reflected in controls over retransfers in our various agreements for cooperation.

Thus, in the case at hand, no Japanese or Swiss spent fuel of U.S. origin, for example, could be retransferred to the USSR for reprocessing and MOX fabrication, etc. etc. until the U.S. has concluded a suitable Agreement for Cooperation with the USSR. In other words, the same inhibition preventing U.S. utilities from sending spent fuel to the USSR would apply 
to countries that have SNM subject to U.S. controls.

Utilities in non-reprocessing states might want to explore the Soviet offer as a way of stimulating competition in a market now controlled by BNFL and Cogema. One cannot fully rule out some Soviet in-roads into the market if the Soviet services are reliable and competitively priced. This, in turn, would raise the question of the adequacy of physical security for Pu returns, among others. If, for example, MOX subject to U.S. consent rights were to be returned from the USSR to Japan with U.S. approval, the U.S. would have to concur in the transportation arrangements. These arrangements would have to conform to the conditions governing plutonium transportation that are set forth in a special annex to the U.S.-Japanese Civil Nuclear Agreement for Cooperation.

It should be noted that U.S. policies towards allowing cooperating countries to have U.S. supplied fuels reprocessed varies between countries depending on their sensitivity from a non-proliferation perspective, whether they are located in sensitive regions of the world, etc. etc. For example, the U.S. strongly encouraged Taiwan and South Korea to refrain from any indigenous reprocessing activities and to remain on a once through fuel cycle and most probably would be very negative about any Soviet overtures to these countries that would involve them being supplied with MOX fuel. Here too, however, it would not be feasible to retransfer U.S. origin spent fuel from South Korea or Taiwan to the USSR in the absence of a U.S.-USSR bilateral nuclear agreement for cooperation and prior U.S. concurrence in such a retransfer.

C. To What Extent are the Services of the USSR Likely to be Extended to Other Countries -Including Those of Possible Proliferation Concern?

The examples of Taiwan and Korea, however, raise the wider question of how broadly the USSR is exploring the marketing of reprocessing and MOX fabrication services and what implications this might have for the global non-proliferation regime. 
Quite obviously, the Soviet offer might extend to countries with whom the U.S. has no civil nuclear relations or it could extend to spent power reactor fuel over which the U.S. has no controls or consent rights. The implications from a non-proliferation and economic perspective would vary with the country specific situations and terms of the Soviet offer.

If the Soviets offered such services to countries like Japan that already are extensively involved in reprocessing and plutonium use, the effects, from a non-proliferation perspective, most likely would be minimal. If the Soviets accepted spent fuel from other countries but opted to keep the plutonium, the arrangements conceivably could be positive from a proliferation standpoint if they served, for example, to prevent a sizeable spent fuel inventory (including its plutonium content) from building up in a non-nuclear weapon state in a volatile location or situation. However, if the Soviet "offer" served (through the return of MOX fuel) to introduce or expand plutonium use in a country of some proliferation concern or sensitivity from a strategic standpoint then such a move would probably be viewed as regressive and unwelcome by the U.S. non-proliferation community. This could be the case even if the MOX was returned in fully fabricated form and was subjected to the application of continual surveillance measures until loaded in a reactor, or if the extension of such Soviet services was instrumental in discouraging indigenous reprocessing in the country involved.

These considerations would suggest that, at the appropriate time, the U.S. should inquire of the Soviets as to the political and non-proliferation criteria they intend to apply in offering their services to other countries. It would be desirable to clarify to which countries they propose to offer such services (including MOX fabrication and supply), what nonproliferation and political conditions they intend to adhere to, and whether they are offering such services to any countries that heretofore have been following a "once through" fuel cycle. It would also be important to know whether the Soviets are offering only a service, or whether they also are willing to contemplate transferring any "sensitive technology" as that term is employed in U.S. circles. Moreover, given current political circumstances in the USSR it would be desirable to clarify the nature of current Soviet institutional controls and 
authority pertaining to nuclear related exports. In this regard, it should be noted that through the years the Soviets generally have been supportive to non-proliferation objectives, including the NPT, and have worked cooperatively with the U.S. in this area. Hopefully, this situation will continue. It remains to be seen, however, whether the current break-up of the USSR and pressures to move to a market economy will lead to any erosion in this picture. This could occur if recent developments weaken effect central export control and if the pressures to earn hard currencies lead to a dominance of commercial considerations over non-proliferation values.

Finally, it also is to be noted that if the USSR moves to supply such fuel cycle services on an active and aggressive basis, this could also serve to strengthen the relative Soviet position as a supplier of enrichment services to the possible disadvantage of the United States.

\section{DISCLAIMER}

This report was prepared as an account of work sponsored by an agency of the United States Government. Neither the United States Government nor any agency thereof, nor any of their employees, makes any warranty, express or implied, or assumes any legal liability or responsibility for the accuracy, completeness, or usefulness of any information, apparatus, product, or process disclosed, or represents that its use would not infringe privately owned rights. Reference herein to any specific commercial product, process, or service by trade name, trademark, manufacturer, or otherwise does not necessarily constitute or imply its endorsement, recommendation, or favoring by the United States Government or any agency thereof. The views and opinions of authors expressed herein do not necessarily state or reflect those of the United States Government or any agency thereof. 